
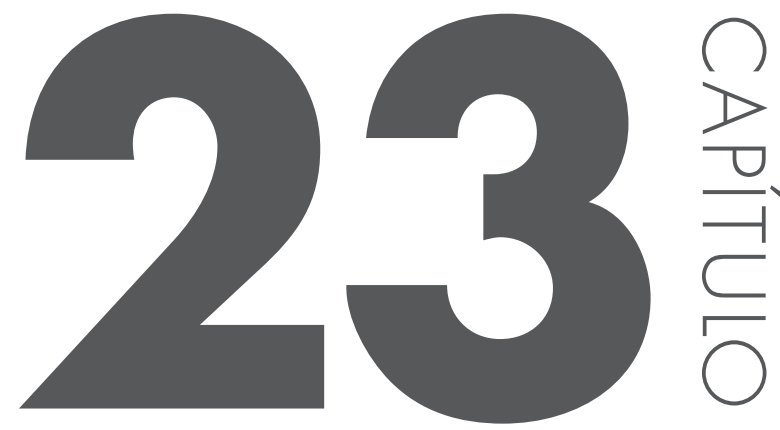

\title{
FÁRMACOS PARA O CONTROLE DA ACIDEZ GÁstrICA E PROTETORES DA MUcosa
}

Flávia Almeida Santos

Vietla Satyanarayana Rao

\subsection{INTRODUC̣ÃO}

A secreção ácida gástrica pelas células parietais do estômago é um processo dinâmico regulado por vias neurais, hormonais e parácrinas, a nível central e periférico, assim como por estímulos mecânicos e químicos. Os principais estimulantes da produção ácida pelas células parietais são a histamina, a acetilcolina e a gastrina.

A secreção ácida estomacal facilita a digestão de proteínas, a absorção de ferro, cálcio e vitamina $\mathrm{B}_{12}$, e reduz o risco de infecções gastrintestinais (Helicobacter pylori, Vibrio cholera, Salmonella sp., dentre outros). Uma secreção ácida insuficiente pode resultar em má absorção e aumento na susceptibilidade a infecções 
gastrintestinais, enquanto excesso de secreção ácida pode causar desde a doença do refluxo gastroesofágico e úlcera péptica até danos mais severos à mucosa como podem ser vistos na síndrome de Zollinger-Ellison.

As principais causas de úlcera péptica são a infecção pelo H. pylori e o uso de anti-inflamatórios não esteroidais (AINEs). O estômago possui sistema de proteção de sua mucosa que envolve a secreção de muco e bicarbonato, a hidrofilicidade da mucosa, a rápida renovação celular epitelial, o fluxo sanguíneo e antioxidantes. A perda ou a redução dos mecanismos de proteção da mucosa tornam as células susceptíveis à ação do ácido clorídrico e da pepsina levando a lesões na mucosa gástrica. Fatores relacionados ao estilo de vida como o fumo, o consumo de bebidas alcoólicas e o estresse também estão associados à formação de úlceras pépticas.

O entendimento da regulação da secreção ácida gástrica levou ao desenvolvimento de terapias supressoras dessa secreção, como os antagonistas dos receptores da histamina $\mathrm{H} 2$ e os inibidores da bomba de prótons (IBPs) que revolucionaram o tratamento das desordens associadas ao crescimento da secreção ácida gástrica.

\subsection{REGULAC̣ÃO DA SECREC̣ÃO ÁCIDA GÁSTRICA}

O estômago pode ser dividido em áreas topográficas (fundo, corpo e antro) e em áreas funcionais (glândulas parietais ou oxínticas e glândulas pilóricas). A área glandular parietal é composta pelas células parietais e compreende $80 \%$ do órgão (fundo e corpo), enquanto a área glandular pilórica é composta pelas células $\mathrm{G}$ ou células de gastrina e compreendem $20 \%$ do órgão (antro).

A região glandular parietal é composta por células mucosas superficiais (produtoras de muco, água e eletrólitos), células mucosas do colo (divisão mitótica), células parietais (produtoras de $\mathrm{HCl}$ e de fator intrínseco), células principais (produtoras de pepsinogênio), células enterocromafins (EC) (contêm peptídeo natriurétrico atrial e adrenomedulina), células semelhantes às enterocromafins (ECL) (contêm histamina), células Gr (que contêm grelina e obestatina). A região glandular pilórica é composta pelas células mucosas superficiais, células mucosas do colo, células G (secretam gastrina), células D (secretam somatostatina) e células EC.

O suco gástrico é composto, principalmente, por ácido clorídrico $(\mathrm{HCl})$, sais, água, pepsina, fator intrínseco, bicarbonato e muco. Os níveis basais de secreção ácida gástrica são de $1-5 \mathrm{mEq} / \mathrm{h}$, podendo atingir $6-40 \mathrm{mEq} / \mathrm{h}$ durante uma estimulação máxima. A secreção de ácido clorídrico pelas células parietais ocorre por meio da $\mathrm{H}^{+}, \mathrm{K}+$-ATPase (bomba de prótons), presente na membrana apical da célula parietal. 
O controle da secreção ácida gástrica pelas células parietais envolve a sinalização neuronal (acetilcolina), hormonal (gastrina) e parácrina (histamina) e pode-se dividir a secreção ácida gástrica em três fases, a Fase cefálica, a Fase gástrica e a Fase intestinal.

O Sistema Nervoso Central (SNC) pode ser considerado o principal iniciador da secreção ácida gástrica em resposta aos estímulos do pensamento, visão, olfato, paladar e de antecipação do alimento, sendo esta a Fase cefálica da secreção ácida. As estruturas mais importantes no SNC envolvidas na estimulação central da secreção de ácido gástrico são o núcleo motor dorsal do nervo vago (NMDV), o hipotálamo e o núcleo do trato solitário (NTS). As fibras eferentes originadas no NMDV, por meio do nervo vago, formam sinapses no estômago com as células ganglionares do sistema nervoso entérico (SNE).

A secreção da Fase cefálica é inteiramente mediada pelo nervo vago, em que a estimulação colinérgica libera acetilcolina ( $\mathrm{ACh}$ ), que atua diretamente nos receptores muscarínicos M3 nas células parietais, estimulando a secreção ácida, além disso, a ACh estimula a liberação de gastrina pelas células G e de histamina pelas células ECL. Em paralelo, a estimulação colinérgica inibe a liberação de somatostatina. O SNE, sob invervação do nervo vago, libera, além da ACh, outros neurotransmissores, incluindo o peptídeo liberador de gastrina (GRP) e o peptídeo ativador da adenilato ciclase pituitária (PACAP), aumentando ainda mais as concentrações locais de gastrina e histamina, respectivamente.

Um rápido aumento na secreção ácida gástrica ocorre durante a Fase gástrica como um resultado dos efeitos do alimento sobre a distensão da parede gástrica e da exposição do lúmen aos nutrientes do alimento. A distensão gástrica por meio dos receptores de estiramento no estômago ativa reflexos vagais que aumentam a secreção ácida estimulada pela $\mathrm{ACh}$ como descrito anteriormente. A exposição do lúmen estomacal a aminoácidos, peptídeos, etanol, cálcio e cafeína contribuem para maior liberação de gastrina. Durante a refeição, o alimento tampona o conteúdo gástrico, elevando o pH luminal, e então permitindo que a secreção gástrica continue.

A Fase intestinal ocorre quando o alimento alcança o duodeno. A resposta geral dessa fase é a inibição da secreção ácida por meio da liberação do peptídeo inibidor gástrico (GIP), da colecistocinina, da secretina e do peptídeo semelhante ao glucagon 1 (GLP-1). Esses hormônios ativam o caminho inibitório da secreção ácida mediado pela somatostatina.

Um importante mecanismo de controle da secreção ácida gástrica ocorre por meio da acidez do lúmen gástrico, que controla a secreção ácida e a liberação de gastrina. Enquanto se observa uma diminuição da liberação de gastrina e da secreção ácida em um valor baixo de $\mathrm{pH}$, o aumento da secreção ácida pode 
ser observado quando o pH intragástrico sobe e a acidez luminal diminui. O aumento da secreção de gastrina e de ácido é observado em um pH intragástrico de 2,5 ou maior, enquanto se observa uma abolição da produção de ácido em um $\mathrm{pH}$ de 1 . O peptídeo relacionado ao gene da calcitonina (CGRP) liberado pelos neurônios sensoriais aferentes gástricos é um dos responsáveis por esse controle de feedback. O CGRP aumenta a liberação de somatostatina, reduzindo a secreção ácida e de gastrina. O mecanismo pelo qual a secreção ácida é aumentada em um pH intragástrico alto ainda não é completamente compreendido.

Os principais estimulantes da secreção ácida pelas células parietais são a histamina, a acetilcolina e a gastrina. A histamina eleva as concentrações intracelulares de AMPc enquanto a acetilcolina e a gastrina elevam as concentrações intracelulares de cálcio, efeitos que acarretam a ativação da bomba de prótons.

A histamina, sintetizada e liberada pelas células ECL é o agonista mais potente da secreção ácida gástrica. As células ECL produzem histamina por meio da descarboxilaçao da L-histidina pela enzima histidina descarboxilase, sendo a fonte primária de histamina gástrica. A histamina estimula diretamente a célula parietal pela ligação aos receptores $\mathrm{H} 2$, acoplados à ativação da adenilil ciclase com produção de AMPc. A histamina também estimula indiretamente a secreção ácida gástrica pela ligação a receptores $\mathrm{H} 3$ que inibem a secreção de somatostatina. Gastrina, PACAP, VIP (peptídeo intestinal vasoativo) e grelina, estimulam a secreção de histamina, enquanto somatostatina, CGRP, prostaglandinas, peptídeo YY e galanina inibem a secreção de histamina.

Os receptores da acetilcolina ( $\mathrm{ACh}$ ), nas células parietais, são do subtipo M3, que são receptores acoplados à proteína $\mathrm{G}$ e à ativação da fosfolipase $\mathrm{C}$, com produção de trifosfato de inositol e aumento do cálcio intracelular. A ACh estimula ainda indiretamente as células parietais, via receptores M2 e M4, acoplados a inibição da secreção de somatostatina pelas células D.

A gastrina, secretada pelas células $G$, na mucosa do antrogástrico, em resposta a estímulos químicos (ex. pH elevado no lúmen gástrico) e mecânicos (ex. distensão gástrica), promove a secreção ácida gástrica primariamente por meio do receptor da colecistocinina 2 (CCK2), estimulando as células ECL a liberarem histamina, que, por sua vez, estimula a secreção ácida.

A gastrina e a colecistocinina (CCK) possuem uma sequência idêntica de peptídeos na porção carboxi-terminal da molécula (-Gly-Trp-Met-Asp-Phe-NH2). As duas classes de receptores gastrina/CCK são os receptores CCK1 (receptor da colecistocinina 1) e os receptores CCK2. Os receptores CCK1 são específicos para a CCK, enquanto os receptores CCK2 reconhecem a CCK e a gastrina. Os receptores CCK2 foram identificados na célula parietal e nas células ECL onde estão acoplados à proteína $\mathrm{G}$, e a ativação da fosfolipase $\mathrm{C}$ com aumento do cálcio 
intracelular. A ativação dos receptores CCK2 nas células parietais leva à secreção ácida gástrica, enquanto a ativação desses receptores nas células ECL leva à liberação de histamina, sendo o principal mecanismo pelo qual a gastrina estimula a secreção ácida. Acetilcolina, GRP, secretina, agonistas adrenérgicos b2/b3 e cálcio estimulam a secreção de gastrina, enquanto somatostatina, galanina e adenosina inibem a secreção de gastrina.

A gastrina age não somente como um segretagogo, mas, na presença de hipergastrinemia, também promove a hipertrofia e a hiperplasia das células ECL e das células parietais, diretamente ou indiretamente via fatores de crescimento (como HBEGF e TGF- $\alpha$ ). A ação trófica da gastrina sobre as células ECL é responsável pela acidez de rebote observada quando os IBPs são retirados abruptamente.

O principal inibidor da secreção ácida gástrica é a somatostatina. A somatostatina, das células D nas glândulas parietais e na mucosa da região pilórica, inibe a secreção ácida pelas células parietais, a secreção de histamina pelas células ECL e de gastrina pelas células G. No estômago, as ações da somatostatina são mediadas pelos receptores da somatostatina do tipo 2 (SST2) que estão ligados com a diminuição dos níveis intracelulares de AMPc. Gastrina, GRP, VIP, PACAP, agonistas adrenérgicos b2/b3, secretina, ANP (peptídeo natriurético atrial), adenomedulina, amilase, adenosina e CGRP estimulam a secreção de somatostatina, enquanto acetilcolina inibe a secreção de somatostatina.

\subsection{FÁRMACOS USADOS PARA O CONTROLE DA ACIDEZ GASTRICA}

\subsubsection{ANTIÁCIDOS}

Os antiácidos são sais inorgânicos, relativamente insolúveis, de alumínio, cálcio, magnésio ou sódio ou uma combinação desses, que neutralizam parcialmente o ácido clorídrico gástrico. Geralmente são necessárias altas doses de antiácidos para aumentar o $\mathrm{pH}$ gástrico de forma significativa. $\mathrm{O}$ aumento do $\mathrm{pH}$ gástrico inibe a atividade da pepsina e a inibição máxima é atingida em um $\mathrm{pH}$ de aproximadamente 4 . A potência antiácida é baseada na equivalência molar para neutralizar uma quantidade conhecida de ácido gástrico, sendo o carbonato de cálcio o mais potente, seguido pelo bicarbonato de sódio, sais de magnésio e sais de alumínio. O hidróxido de alumínio e o hidróxido de magnésio/alumínio possuem propriedades citoprotetoras que se devem a um aumento na secreção de bicarbonato gástrico, na liberação de prostaglandinas e em adição no aumento da secreção de muco e do fluxo sanguíneo microvascular. 
Os antiácidos mais comumente utilizados são os sais de magnésio e os sais de alumínio. O hidróxido de magnésio rapidamente reage com o ácido gástrico produzindo cloreto de magnésio e água. Quando o carbonato de magnésio reage com o ácido clorídrico, é produzido dióxido de carbono em adição aos demais produtos de reação. Hidróxido de alumínio e óxido de alumínio reagem com o ácido gástrico para produzir cloreto de alumínio e água. Carbonato de alumínio produz dióxido de carbono, cloreto de alumínio, água e o fosfato de alumínio produzem cloreto de alumínio e ácido fosfórico.

Em adição ao efeito de redução da atividade da pepsina, os antiácidos de alumínio e de magnésio são ainda capazes de adsorverem a pepsina. Antiácidos de alumínio ligam-se aos fosfatos da dieta formando fosfato de alumínio insolúvel, o que pode resultar em diminuição da absorção de fosfato, hipofosfatemia e hipofosfatúria em pacientes com função renal normal, característica pela qual o hidróxido de alumínio pode ser utilizado para reduzir a hiperfosfatemia em pacientes com insuficiência renal crônica.

As interações medicamentosas envolvendo antiácidos ocorrem por sua ligação com outros fármacos no trato gastrintestinal, pela alteração do $\mathrm{pH}$ gastrintestinal e do $\mathrm{pH}$ urinário.

$\mathrm{O}$ aumento do $\mathrm{pH}$ gástrico, induzido pelo antiácido, pode alterar o grau de ionização, assim como a dissolução de fármacos que são dependentes de um pH gástrico baixo por exemplo, o cetoconazol que tem sua desintegração e dissolução prejudicadas pelo aumento do $\mathrm{pH}$ gástrico. O contrário também pode ser observado, a absorção da amoxicilina é aumentada quando o pH gástrico é elevado.

Os antiácidos adsorvem fármacos de forma inespecífica, por exemplo, os hidróxidos de alumínio e de magnésio prejudicam a absorção da fenitoína. Antiácidos com cátions divalentes e trivalentes podem reduzir a absorção de fármacos, por exemplo, a formação de complexos de antiácidos de magnésio, alumínio e cálcio com a tetraciclina.

Os antiácidos de magnésio e de alumínio podem elevar o pH urinário alterando a ionização de fármacos no túbulo renal, desse modo aumentando (p. ex. quinidina) ou diminuindo (p. ex. salicilatos) sua reabsorção.

O principal efeito adverso dos antiácidos que contêm alumínio é a constipação, pela formação de sais de alumínio insolúveis. Aproximadamente 17-30\% do cloreto de alumínio produzido é absorvido sistemicamente. O alumínio é rapidamente eliminado em pacientes com função renal normal, contudo pode ser retido no cérebro e em outros tecidos em pacientes com insuficiência renal.

A diarreia é o efeito adverso mais comum para os antiácidos que contêm magnésio, causada pela baixa absorção dos sais de magnésio relativamente insolúveis e pelo subsequente efeito osmótico no intestino. Em virtude do fato de 
que $5-10 \%$ do cloreto de magnésio produzido no trato gastrintestinal pode ser absorvido sistemicamente, pode-se observar hipermagnesemia em pacientes com insuficiência renal.

A fim de minimizar os efeitos sobre o trato gastrintestinal, os antiácidos mais utilizados são associações de hidróxido de magnésio e de alumínio.

As principais indicações terapêuticas dos antiácidos ocorrem no tratamento da doença ulcerosa péptica, da doença do refluxo gastroesofágico e da dispepsia.

\subsubsection{ANTAGONISTAS DOS RECEPTORES H2 DA HISTAMINA}

Os bloqueadores dos receptores $\mathrm{H} 2$ da histamina em uso clínico são a cimetidina, a ranitidina, a famotidina e a nizatidina (Figura 23.1).

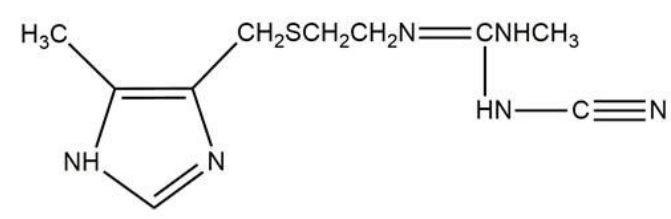

Cimetidina

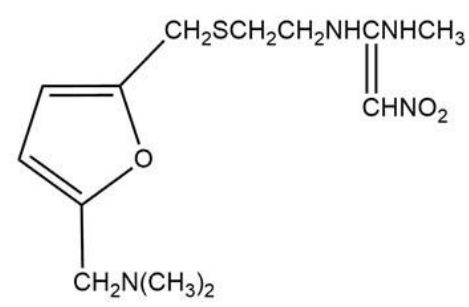

Ranitidina

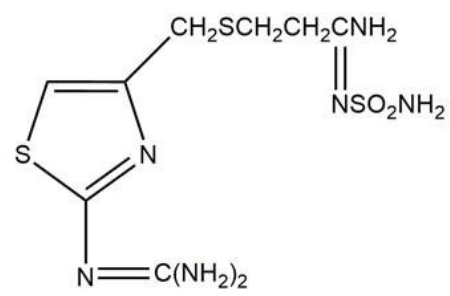

Famotidina

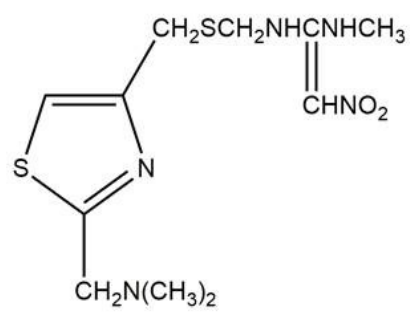

Nizatidina

Figura 23.1 - Estrutura química dos antagonistas dos receptores H2

Os bloqueadores $\mathrm{H} 2$ inibem de forma seletiva e competitiva a ligação da histamina aos receptores $\mathrm{H} 2$ gástricos reduzindo a secreção ácida pelas células parietais. A histamina, ao ligar-se ao receptor $\mathrm{H} 2$ na célula parietal, eleva a produ- 
ção de AMPc, que, por meio da ativação da proteína cinase A (PKA), fosforila as proteínas envolvidas com o transporte da bomba de prótons do citoplasma para a membrana plasmática da célula parietal.

A famotidina é a que possui maior potência relativa para a inibição da secreção ácida, enquanto a cimetidina é a menos potente. Ranitidina e nizatidina possuem potências iguais. Como resultado da redução da secreção ácida e do aumento do $\mathrm{pH}$ gástrico, os bloqueadores $\mathrm{H} 2$ tendem a aumentar a concentração sérica da gastrina, além de reduzirem a atividade péptica por uma redução na secreção do pepsinogênio.

A absorção de cimetidina, ranitidina e famotidina é rápida. Enquanto cimetidina, ranitidina e famotidina sofrem extenso metabolismo de primeira passagem com biodisponibilidade entre $43-60 \%$ após administração oral, a nizatidina sofre pouco desse metabolismo e apresenta biodisponibilidade de aproximadamente $100 \%$. O pico de concentração plasmática dos bloqueadores H2 ocorre entre 1-3h após administração oral. A ligação às proteínas plasmáticas é de 13-35\%. Todos os fármacos são encontrados no líquido cefalorraquidiano, atravessam a barreira placentária e são excretados no leite.

Embora existam consideráveis diferenças no clearance e na meia-vida de eliminação dos bloqueadores $\mathrm{H} 2$, a meia-vida no soro varia de 1,5-4h em indivíduos normais. A eliminação ocorre por uma combinação de metabolismo hepático, filtração glomerular e secreção tubular renal. O clearance renal dos quatro fármacos é de duas a três vezes maior que o clearance da creatinina, refletindo a extensa secreção tubular renal.

A distribuição da cimetidina leva à extensa captação pelos rins, pulmões e tecido muscular. O volume de distribuição é da ordem de $1 \mathrm{~L} / \mathrm{Kg}$. O tempo de meia-vida é de aproximadamente $2 \mathrm{~h}$ e a ligação às proteínas plasmáticas é de $20 \%$. Sua distribuição no líquido cefalorraquidiano é aumentada na doença hepática severa, devendo a dose ser reduzida nesses pacientes para evitar a confusão mental, enquanto o volume de distribuição é diminuído em aproximadamente $40 \%$ no idoso. Entre $50-80 \%$ da dose administrada por via intravenosa são recuperadas inalteradas da urina. Essa fração é menor após uma administração oral, mas é independente da quantidade da dose. Em pacientes com úlceras gástricas, $40 \%$ é recuperado inalterado na urina após administração oral. A excreção biliar da cimetidina ocorre para apenas $2 \%$ da dose.

Os principais fatores, relacionados ao paciente, que alteram a farmacocinética dos bloqueadores $\mathrm{H} 2$ são a idade e a função renal. A idade deve ser considerada quando esses fármacos são usados em pacientes pediátricos e geriátricos, em que neonatos requerem menores doses devido à redução da secreção renal. Nos idosos observa-se uma redução no clearance por uma redução da função renal. A 
meia vida é aumentada e o clearance é reduzido em pacientes com insuficiência renal. Em geral, o tempo de meia-vida pode ser aumentado em 2 a 6 vezes, sendo recomendadas, em pacientes com insuficiência renal, reduções nas doses administradas. Os efeitos adversos mais comuns são diarreia, cefaleia, sonolência, fadiga, dor muscular e constipação. Outros efeitos adversos que ocorrem em menor número de pacientes são confusão mental, tontura, ginecomastia, galactorreia, impotência, perda da libido, neutropenia, trombocitopenia, agranulocitose, elevação de enzimas hepáticas, febre, reações alérgicas, aumento da creatinina sérica, nefrite intersticial, artralgia mialgia, bradicardia, taquicardia, hipotensão e arritmias cardíacas. Embora alguns desses efeitos adversos sejam relacionados ao bloqueio $\mathrm{H} 2$, muitos deles podem se dever a reações idiossincráticas.

Os bloqueadores $\mathrm{H} 2$ apresentam potencial de alterar a absorção de fármacos pela elevação do pH gástrico. Cimetidina, por exemplo, reduz a absorção do cetoconazol, enquanto a metoclopramida pode reduzir a absorção dos bloqueadores $\mathrm{H} 2$.

A cimetidina, e a ranitidina, em menor extensão, aumentam as concentrações séricas de prolactina, especialmente em altas doses, o que contribui para os sintomas de galactorréia na mulher e de ginecomastia no homem. A impotência e a perda da libido em homens, em uso da cimetidina, ocorrem mais frequentemente com o uso de altas doses por longos períodos. A cimetidina inibe a ligação da dihidrotestosterona aos receptores androgênicos, um efeito não observado com os demais bloqueadores $\mathrm{H} 2$, e inibe o metabolismo do estradiol no homem.

Numerosas interações medicamentosas foram descritas com os bloqueadores $\mathrm{H} 2$, mais frequentemente com a cimetidina. A cimetidina pode reduzir o metabolismo de um número de fármacos pela inibição das enzimas do citocromo P450, contudo os efeitos adversos provenientes dessa interação são mais importantes com pacientes em uso de varfarina, teofilina e fenitoína. A cimetidina pode ainda reduzir a metabolização hepática e aumentar a concentração sérica da cafeína, carbamazepina, propanolol, nifedipina, lidocaína, quinidina, imipramina, desipramina, triazolam e metronidazol. A ranitidina, apesar de ser mais potente que a cimetidina, possui menor potencial de alterar o metabolismo de outros fármacos por se ligar de 5 a 10 vezes com menor avidez ao CYP450. Famotidina e nizatidina apresentam baixo potencial de inibição das enzimas do citocromo P450 e desse modo, apresentam potencial limitado sobre o metabolismo de outros fármacos.

Os barbitúricos podem aumentar o metabolismo dos bloqueadores $\mathrm{H} 2$, o que pode ser observado na resposta inadequada da cimetidina ao ser administrada concomitantemente com o fenobarbital.

Os bloqueadores $\mathrm{H} 2$ competem com compostos catiônicos pela secreção tubular renal. Cimetidina e ranitina competem com a creatinina pela secreção tu- 
bular renal, o que eleva em $15 \%$ os níveis séricos da creatinina, com redução no seu clearance.

As principais indicações terapêuticas dos bloqueadores $\mathrm{H} 2$ referem-se à doença ulcerosa péptica e à doença do refluxo gastroesofágico e à dispepsia.

\subsubsection{INIBIDORES DA BOMBA DE PRÓTONS}

Os inibidores da bomba de prótons (IBPs) são os principais fármacos utilizados no tratamento das doenças relacionadas ao cresciento da secreção ácida gástrica. Desde a introdução do omeprazol, outros IBPs tornaram-se disponíveis, o lansoprazol, o pantoprazol, o rabeprazol, o esomeprazol ( $S$-enantiômero do omeprazol) e o dexlansoprazol ( $R$-enantiômetro do lansoprazol) (Figura 23.2).

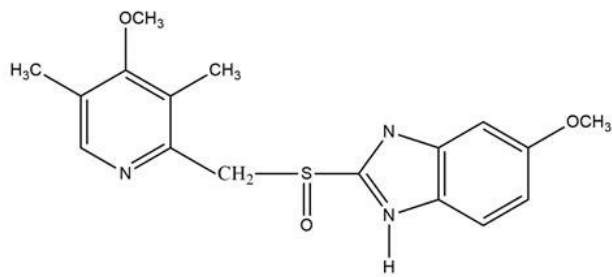

Omeprazol<smiles>COc1ccc2[nH]c(S(=O)Cc3nccc(OC)c3OC)nc2c1</smiles>

Pantoprazol<smiles>Cc1c(OCC(F)(F)F)ccnc1CSc1nc2ccccc2[nH]1</smiles>

Lansoprazol<smiles>COCCCOc1ccnc(CS(=O)c2nc3ccccc3n2N)c1C</smiles>

Rabeprazol<smiles>Cc1c(OCC(F)(F)F)ccnc1CS(=O)c1nc2ccccc2[nH]1</smiles>

Dexlansoprazol

Figura 23.2 - Estrutura química dos inibidores da bomba de prótons.

Os IBPs inibem, irreversivelmente, a $\mathrm{H}+, \mathrm{K}+-\mathrm{ATPase}$ (bomba de prótons) gástrica, que realiza a etapa final da secreção ácida. Todos os IBPs inibem a secre- 
ção ácida gástrica basal e estimulada, independentemente da natureza da estimulação da célula parietal.

A H+, K+-ATPase gástrica é composta de duas subunidades, a subunidade catalítica $\alpha$ que é responsável pelas funções catalíticas e de transporte, e a subunidade $\beta$ que possui as funções estruturais e de ligação à membrana. A bomba de prótons está inativa quando presente no citoplasma como parte da membrana tubular e quando separada dos canalículos, contudo, quando presente na membrana dos canalículos, a bomba de prótons secreta ativamente o ácido clorídrico, promovendo a troca de próton intracelular por potássio extracelular. O ATP catalisa a troca de $\mathrm{H}+$ por $\mathrm{K}+$ na ordem de $2 \mathrm{H}+/ 2 \mathrm{~K}+/ \mathrm{ATP}$ a $\mathrm{pH} 6,1$ que cai para $1 \mathrm{H}+/ 1 \mathrm{~K}+/ \mathrm{ATP}$ quando o $\mathrm{pH}$ luminal cai abaixo de 3 .

Os IBPs são benzimidazóis substituídos e como pró-fármacos necessitam de ativação em ambiente ácido. Por serem bases fracas, os IBPs são acumulados nos canalículos secretórios ácidos da célula parietal, onde sofrem ativação por meio de uma protonação, com formação de sulfenamida cíclica, que se liga aos resíduos de cisteína, em especial à cisteína 813 , da subunidade $\alpha$ da bomba de prótons, inibindo-a de forma seletiva e irreversível.

Apesar de os IBPs possuírem um tempo de meia-vida curto $(0,5-2 \mathrm{~h})$, a ação antissecretória pode durar até 24-48h, como um resultado da inibição irreversível da bomba de prótons. O potencial inibitório máximo será observado aproximadamente após três a quatro dias, até que se observe um equilíbrio entre a inibição covalente das bombas de prótons ativas, a subsequente estimulação de bombas inativas e a síntese de novo de novas bombas.

O omeprazol é uma mistura racêmica de dois enantiômeros, $S$-omeprazol (esomeprazol) e $R$-omeprazol. O lansoprazol é uma mistura racêmica de seus dois enantiômetros, enquanto o dexlanzoprazol é constituído pelo enantiômetro $R$ do lansoprazol ( $R$-lansoprazol).

O dexlansoprazol ao contrário dos demais IPBs é formulado com dois tipos de grânulos de revestimento entérico que são solúveis em diferentes valores de $\mathrm{pH}$, sendo inicialmente liberado no intestino delgado proximal após 1-2h da sua administração, tendo uma segunda liberação do fármaco 4-5h depois na região distal do intestino delgado.

A biodisponibilidade dos IBPs varia de 30-85\%, enquanto a ligação às proteínas plasmáticas está de 95-98\%.

Omeprazol, esomeprazol, lansoprazol, pantoprazol e dexlansoprazol são metabolizados pelas enzimas do citocromo P450, CYP2C19 e CYP3A4. Omeprazol é convertido principalmente a metabólitos hidroxi e 5-O-desmetil pelo CYP2C19 e a sulfona pelo CYP3A4. O esomeprazol é predominantemente metabolizado pelo CYP3A4 e consequentemente menos dependente do CYP2C19. 
O lansoprazol é extensiva e rapidamente metabolizado em metabólicos sulfonas e 5-hidroxilados. O pantoprazol é completamente metabolizado, sofrendo principalmente $\mathrm{O}$-demetilação, seguida por conjugação com sulfato e formação de sulfonas. Metabólitos oxidados do dexlansoprazol são formados por meio de hidroxilação pela CYP2C19 e oxidação a sulfona via CYP3A4.

O metabolismo do rabeprazol ocorre por um caminho não enzimático, principalmente pela sua redução a rabeprazol tioéter. Aproximadamente, $90 \%$ da dose é eliminada na urina na forma de ácido mercaptúrico conjugado e ácido carboxílico. O CYP2C19 e CYP3A4 contribuem somente para uma pequena fração de seu metabolismo. Desse modo, o rabeprazol é menos susceptível a receber influência no seu metabolismo na ocorrência de polimorfirmos genético do CYP2C19 ou CYP3A4 do que os demais IBPs. A excreção dos IBPs é principalmente urinária.

A elevação do $\mathrm{pH}$ gástrico induzida pelos IBPs pode afetar a absorção de alguns fármacos, por exemplo, cetoconazol, digoxina, ésteres de ampicilina e sais de ferro. Lansoprazol, pantoprazol, rabeprazol e dexlansoprazol estão associados com baixa incidência de interações medicamentosas quando comparados ao omeprazol e ao esomeprazol.

O omeprazol pode inibir a metabolização hepática de fármacos, como diazepam, fenitoína e varfarina, pela inibição competitiva do CYP2C19. Cetoconazol, fluconazol, claritromicina e moclobemida que possuem alta afinidade pelo CYP3A4 podem aumentar a concentração sérica do omeprazol, mas esse efeito é importante apenas nos indivíduos com deficiência de CYP2C19. Em geral, pode-se esperar que o potencial de interações medicamentosas do esomeprazol seja similar ao do omeprazol.

Os IBPs podem alterar a farmacocinética de inibidores de proteases, como atazanavir, endinavir, nelfinavir, raltegravir e ritonavir.

$\mathrm{Na}$ terapia com omeprazol/claritromicina/amoxicilina usada na erradicação do H. pylori, o sinergismo farmacodinâmico desses fármacos deve-se, em parte, a interações farmacocinéticas, uma vez que a área sob a curva (AUC) do omeprazol aumenta quase duas vezes após a administração concomitante com claritromicina.

Alguns estudos demonstraram efeitos controversos em relação à interação medicamentosa entre clopidogrel e IBPs. Clopidrogel é um antiagregante plaquetário, usado na profilaxia de evento cardiovascular isquêmico e que pode ser usado em associação ao ácido acetilsalić́lico (AAS). Quando clopidogrel e AAS são usados em conjunto, recomenda-se o uso de um IBP devido ao risco de sangramento gastrintestinal. Clopidogrel é uma pró-droga, e a enzima envolvida na sua ativação, o CYP2C19, pode ser inibida pelos IBPs. Apesar de alguns estudos demonstrarem uma interação entre clopidogrel e IBPs (principalmente com omeprazol) com redução da eficácia do clopidogrel e aumento do risco de efeitos cardio- 
vasculares, outros estudos não mostraram essa correlação, sendo desaconselhado seu uso com omeprazol ou esomeprazol e considerado o uso do pantoprazol que possui comparativamente menor atividade inibitória sobre a CYP2C19.

Os efeitos adversos mais comuns dos IBPs são cefaleia, diarreia, rash cutâneo, dor abdominal, flatulência, náuseas e constipação. Dentre os efeitos adversos raros, temos hipergastrinemia, síndrome da hipersecreção ácida de rebote, osteoporose, fraturas de quadril e vértebras, infecções entéricas (p.ex. Clostridium diff(cile), pneumonia, hipomagnesemia e hipocalcemia.

A terapia com antissecretórios pode levar a hipergastrinemia, hiperplasia da mucosa e aumento da massa de células ECL, que resulta no aumento da capacidade de secreção ácida gástrica. A hipersecreção ácida de rebote associada ao uso de IBPs pode ser observada dentro de 14 dias após a descontinuação da terapia, e com sintomas como azia, regurgitação ácida e dispepsia, resultando em reintrodução da terapia.

As principais indicações terapêuticas dos IBPs referem-se ao tratamento da doença ulcerosa péptica, à doença do refluxo gastroesofágico, à dispepsia e à síndrome de Zollinger-Ellison.

\subsection{FÁRMACOS PROTETORES DA MUCOSA}

A mucosa gástrica é continuamente exposta a substâncias nocivas, como o ácido clorídrico, a pepsina. A manutenção de sua integridade estrutural ocorre por meio de mecanismos de defesa. O epitélio gástrico secreta uma barreira de proteção que consiste de água, glicoproteínas ou mucinas, bicarbonato, fosfolipideos, fatores trefoil, prostaglandinas e proteínas do choque térmico. As junções intracelulares do epitélio gástrico e a microcirculação da submucosa fornecem oxigênio, bicarbonato e nutrientes enquanto removem toxinas e íons $\mathrm{H}^{+}$. A renovação celular contínua promove uma linha adicional de defesa da mucosa. A defesa da mucosa duodenal similarmente consiste em fatores como a secreção de bicarbonato, a prevenção da acidificação intracelular, a ativação neuronal e o fluxo sanguíneo. Além disso, a defesa gastroduodenal envolve a neutralização de espécies reativas de oxigênio, respostas imune inata e adaptativa e inibição da apoptose.

A injúria da mucosa pode ocorrer quando os mecanismos de defesa são comprometidos por agentes nocivos como o ácido gástrico, antiinflamatórios não esteroidais (AINEs) e Helicobacter pylori.

Pode-se chamar atenção para o mecanismo de defesa da mucosa gástrica envolvendo a barreira muco-bicarbonato, uma vez que os fármacos protetores da mucosa disponíveis agem, principalmente, por meio desse mecanismo. 
A mucosa gastroduodenal ajusta seus mecanismos de defesa de acordo com o pH luminal e mantém o balanço ácido-base aumentando a absorção de ácido luminal e a secreção de bicarbonato.

As prostaglandinas (PGs), em especial a PGE2, desempenham importante papel na modulação da integridade da mucosa e de várias funções do trato gastrintestinal, como a regulação da secreção de bicarbonato gastroduodenal. Os receptores para a PGE2 são receptores acoplados à proteína $G$, e estão expressos em todo o trato gastrintestinal, incluindo a mucosa gástrica e duodenal. A ativação dos receptores EP1 leva ao aumento da secreção de bicarbonato gástrico via sinalização do cálcio intracelular, enquanto, para o aumento da secreção de bicarbonato duodenal, ocorre o aumento intracelular do AMPc e do cálcio via receptores EP3 e EP4. Além das PGs, outros mediadores, como o óxido nítrico (NO), podem mediar aspectos fisiológicos da defesa da mucosa.

\subsubsection{SAIS DE BISMUTO}

Os sais de bismuto são utilizados com sucesso na gastroenterologia desde o século XIX. Foram inicialmente introduzidos no tratamento da dispepsia e da doença ulcerosa péptica, mas o bismuto também possui uma história de uso como antimicrobiano, especialmente no tratamento da sífilis, assim como no tratamento de todos os tipos de diarreia, como na prevenção e tratamento da diarreia do viajante. $\mathrm{O}$ conhecimento da ação antimicrobiana do bismuto posteriormente levou ao seu uso no tratamento da infecção pelo H. pylori. Adicionalmente, estudos mostram o seu benefício na colite microscópica.

Os sais de bismuto são o subsalicilato de bismuto, o subcitrato de bismuto coloidal e o citrato de bismuto. O subsalicilato de bismuto (SSB) é um complexo insolúvel de bismuto trivalente e salicilato, que reage com o ácido gástrico formando oxicloreto de bismuto ( $\mathrm{BiOCl}$ ) e ácido salicílico, que é absorvido no estômago e intestino. O SSB não hidrolisado pode reagir com outros ânions como o bicarbonato e o fosfato para formar subcarbonato de bismuto e sais de fosfato de bismuto. O SSB, o $\mathrm{BiOCl}$ e os outros sais de bismuto reagem com o sulfeto de hidrogênio no cólon produzindo sulfeto de bismuto, que é o responsável pelo escurecimento das fezes decorrente do uso do subsalicilato de bismuto.

O subcitrato de bismuto coloidal (SBC) é um complexo de sal de bismuto do ácido cítrico, que no estômago forma $\mathrm{BiOCl}$ e várias estruturas contendo grupos carboxila livres e positivamente carregados. A ação do SBC é similar à do SSB, formando vários complexos de bismuto, assim como sulfeto de bismuto nas fezes.

$\mathrm{O}$ citrato de bismuto ranitidina é um complexo de ranitina (antagonista $\mathrm{H} 2$ ), bismuto trivalente e citrato, cuja inibição da secreção ácida gástrica ocorre por 
antagonismo no receptor $\mathrm{H} 2$ na célula parietal gástrica, além de efeito protetor da mucosa e ação contra o $H$. pylori.

Os mecanismos moleculares das ações dos sais de bismuto sobre o $H$. pylo$r i$ envolvem a inibição de enzimas produzidas pelo $H$. pylori incluindo urease, catalase e lipase/fosfolipase; inibição da adesão do H. pylori a superfície das células epiteliais; inibição da síntese de ATP, inibição de proteínas e da síntese da parede celular e função de membrana. Adicionalmente, os sais de bismuto possuem ação citoprotetora e inibidora da secreção ácida gástrica. A inibição de um espectro de proteases, a modulação do estresse oxidativo celular e a interferência com a homeostase do níquel parecem ser os principais mecanismos moleculares dos sais de bismuto sobre o H. pylori.

O bismuto coloidal inibe a atividade da pepsina, liga-se aos sais biliares e aumenta a produção de muco. O bismuto coloidal aumenta de maneira dose e tempo-dependente a síntese e a secreção de prostaglandinas no trato gastrintestinal superior, em especial de PGE2 endógena na mucosa antral gástrica e aumento na secreção de bicarbonato pela mucosa gastroduodenal.

Como efeitos adversos, temos tontura, cefaleia, náuseas, vômitos, diarreia e distúrbio psicótico. O escurecimento das fezes é comum devido à formação do sulfeto de bismuto. Como eventos raros, temos o rash cutâneo e o escurecimento de dentes e língua.

Os efeitos tóxicos relacionados a uma overdose de compostos de bismuto incluem encefalopatia, nefropatia, osteoartropatia, gengivoestomatite e colite. Esses eventos raramente são vistos com o uso de doses terapêuticas de sais de bismuto, uma vez que apenas pequenas quantidades desses compostos são absorvidos no trato gastrointestinal.

\subsubsection{SUCRALFATO}

O sucralfato, um sal complexo de sulfato de sacarose e hidróxido de alumínio (Figura 23.3), é um citoprotetor utilizado para prevenir ou tratar a doença do refluxo gastroesofágico, a doença ulcerosa péptica e a dispepsia, além de ter se mostrado útil em pacientes com colite ulcerativa. 


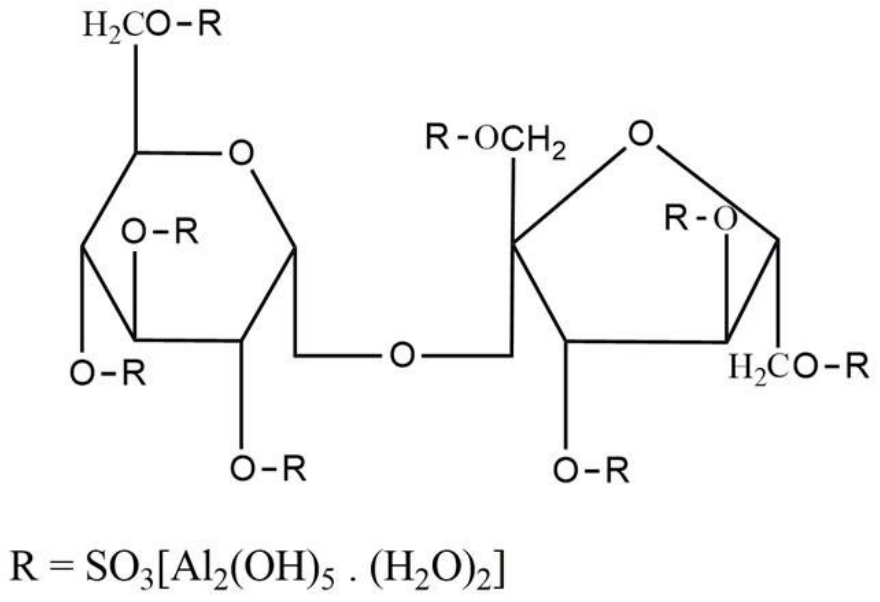

SUCRALFATO

Figura 23.3 - Estrutura química do sucralfato.

O sucralfato tem baixa solubilidade em água e, quando dissolvido, em meio ácido ou alcalino, é dissociado em sal de alumínio e sulfato de sacarose, formando uma substância semelhante a um gel de poliânions que se liga com alta afinidade à mucosa normal e lesionada. Na presença de ácido, o composto libera alumínio que adquire carga negativa e se liga eletrostaticamente a grupos químicos carregados positivamente, incluindo proteinas, peptideos, drogas e metais proporcionando a formação de um gel que protege a mucosa contra a ação do ácido clorídrico, pepsina e sais biliares.

As principais ações do sucralfato que contribuem para a sua eficácia clínica são a inibição da digestão péptica (especialmente pela pepsina $\mathrm{A}$ ); os vários efeitos sobre a composição química, estrutura física e resistência à degradação da barreira gel-muco; a estimulação da liberação de prostaglandinas e, consequentemente, da secreção de bicarbonato, produção de muco, fluxo sanguíneo e divisão celular; a estimulação da produção de muco e bicarbonato independentemente de prostaglandinas e os efeitos sobre o crescimento celular, regeneração e reparo da mucosa (se liga a fatores de crescimento, como FCFb e PDGF, estimulando a angiogênese, a produção de tecido de granulação, levando à reepitelização e ao reestabelecimento da integridade da mucosa gastroduodenal). 
O sucralfato é uma droga segura e bem tolerada, e seu principal efeito adverso é a constipação. Outros efeitos adversos incluem boca seca, náuseas, vômitos, cefaléia, urticária e rash cutâneo.

A absorção e a biodisponibilidade de alguns fármacos podem ser reduzidas quando administrados em combinação com fluoroquinolonas, aminofilina, teofilina, tetraciclinas, cetoconazol, fenitoína, digoxina, levotiroxina, cimetidina, ranitidina e amitriptilina.

\section{REFERÊNCIAS BIBLIOGRÁFICAS}

AKIBA, Y.; KAUNITZ, J. D. Luminal chemosensing and upper gastrointestinal mucosal defenses. The American Journal of Clinical Nutrition. 90(3): 826S-831S, 2009.

ANDERSSON, T. Pharmacokinetics, metabolism and interactions of acid pump inhibitors. Focus on omeprazole, lansoprazole and pantoprazole. Clinical Pharmacokinetics. 31(1): 9-28, 1996.

ARMSTRONG, J. A.; WEE, S. H.; GOODWIN, C. S.; WILSON, D. H. Response of Campylobacter pyloridis to antibiotics, bismuth and an acid-reducing agent in vitro-an ultrastructural study. Journal of Medical Microbiology. 24(4): 343-350, 1987.

ATKINSON, N. S.; REYNOLDS, D. J.; TRAVIS, S. P. Lemonade Legs: Why do Some Patients Get Profound Hypomagnesaemia on Proton-Pump Inhibitors?. Intestinal Research. 13(3): 227-232, 2015.

BARRETT, T. D.; LAGAUD, G.; WAGAMAN, P.; FREEDMAN, J. M.; YAN, W.; ANDRIES, L.; RIZZOLIO, M. C.; MORTON, M. F.; SHANKLEY, N. P. The cholecystokinin CCK2 receptor antagonist, JNJ-26070109, inhibits gastric acid secretion and prevents omeprazole-induced acid rebound in the rat. British Journal of Pharmacology. 166(5): 1684-1693, 2012.

CABOCLO, J. L.; CURY, FDE. A.; BORIN, A. A.; CABOCLO, L. O.; RIBEIRO, M. F.; DE FREITAS, P. J.; ANDERSSON, S. Gastric secretion elicited by conditioning in rats. Scandinavian Journal of Gastroenterology. 44(6): 672$679,2009$. 
CANDELLI, M.; CARLONI, E.; ARMUZZI, A.; CAMMAROTA, G.; OJETTI, V.; PIGNATARO, G.; SANTOLIQUIDO, A.; POLA, R.; POLA, E.; GASBARRINI, G.; GASBARRINI A. Role of sucralfate in gastrointestinal diseases. Panminerva Medica. 42(1): 55-59, 2000.

CARDOSO, R. N.; BENJO, A. M.; DINICOLANTONIO, J. J.; GARCIA, D. C.; MACEDO, F. Y.; EL-HAYEK, G.; NADKARNI, G. N.; GILI, S.; IANNACCONE, M.; KONSTANTINIDIS, I.; REILLY, J. P. Incidence of cardiovascular events and gastrointestinal bleeding in patients receiving clopidogrel with and without proton pump inhibitors: an updated metaanalysis. Open Heart. 2(1): e000248, 2015.

CENGIZ, N.; USLU, Y.; ·GÖK, F.; Anarat, A. Acute renal failure after overdose of colloidal bismuth subcitrate. Pediatric Nephrology. 20(9): 1355-1358, 2005.

CHU, S.; SCHUBERT, M. L. Gastric secretion. Current Opinion in Gastroenterology. 28(6): 587-593, 2012.

DEFONESKA A.; KAUNITZ, J.D. Gastroduodenal mucosal defense. Current Opinion in Gastroenterology. 26(6): 604-610, 2010.

DELITAlA, G.; DEVILlA, L.; PENDE, A.; CANESSA, A. Effects of the H2 receptor antagonist ranitidine on anterior pituitary hormone secretion in man. European Journal of Clinical Pharmacology. 22(3): 207-211, 1982.

DREWELOW, B.; SCHAFFLER, K.; REITMEIR, P.; BETHKE, T. D. Effects of multiple-dose esomeprazole and pantoprazole on diazepam pharmacokinetic profile and pharmacodynamic effects on cognitive and psychomotor function in healthy volunteers. Arzneimittelforschung. 60(8): 483-491, 2010.

DUBB, J. W.; STOTE, R. M.; FAMILIAR, R. G.; LEE, K.; ALEXANDER, F. Effect of cimetidine on renal function in normal man. Clinical Pharmacology and Therapeutics. 24(1): 76-83, 1978.

EMERSON, C. R.; MARZELLA, N. Dexlansoprazole: A proton pump inhibitor with a dual delayed-release system. Clinical Therapeutics. 32(9): 1578-1596, 2010. 
EOM, C. S.; JEON, C. Y.; LIM, J. W.; CHO, E. G.; PARK, S. M.; LEE, K. S. Use of acid-suppressive drugs and risk of pneumonia: a systematic review and meta-analysis. Canadian Medical Association Journal. 183(3): 310-319, 2011.

ERICSSON, P.; HAKANSON, R.; REHFELD, J. F.; NORLÉN, P. Gastrin release: antrum microdialysis reveals a complex neural control. Regulatory Peptides. 161(1-3): 22-32, 2010.

FELDMAN, M.; BURTON, M.E. Histamine2-receptor antagonists. Standart therapy for acid-peptic diseases. 1. New England Journal of Medicine. 323(24): 1672-1680, 1990.

FORDTRAN, J. S.; MORAWSKI, S. G.; RICHARDSON, C. T. In vivo and in vitro evaluation of liquid antacids. The New England Journal of Medicine. 288(18): 923-928, 1973.

FREEDBERG, D. E.; LEBWOHL, B.; ABRAMS, J. A. The impact of proton pump inhibitors on the human gastrointestinal microbiome. Clinics in Laboratory Medicine. 34(4): 771-785, 2014.

GALBRAITH, R. A.; MICHNOVICZ, J. J. The effects of cimetidine on the oxidative metabolism of estradiol. New England Journal of Medicine. 321(5): 269-274, 1989.

GARCÍA RODRÍGUEZ, L. A.; JICK, H. Risk of gynaecomastia associated with cimetidine, omeprazole, and other antiulcer drugs. British Medical Journal. 308(6927): 503-506, 1994.

GE, R.; SUN, H. Bioinorganic chemisry of bismuth and antimony: target sites of metallodrugs. Accounts of Chemical Research. 40(4): 267-274, 2007.

GE, R.; SUN, X.; GU, Q.; WATT, R. M.; TANNER, J. A;WONG, B. C.,; XIA, H. H.; HUANG, J. D.; HE, Q. Y.; SUN, H. A proteomic approach for the identification of bismuth-binding proteins in Helicobacter pylori. Journal of Biological Inorganic Chemistry. 12(6): 831-842, 2007.

GE, R.; CHEN, Z.; ZHOU, Q. The actions of bismuth in the treatment of Helicobacter pylori infections: an update. Metallomics. 4(3): 239-243, 2012. 
GOODWIN, C. S.; ARMSTRONG, J. A.; COOPER, M. Colloidal bismuth subcitrate inhibits the adherence of $\mathrm{H}$. Pylori to epithelial cells. Italian Journal of Gastroenterology. 23(Suppl. 2): 40, 1991.

JAIN, R. N.; SAMUELSON, L. C. Differentiation of the gastric mucosa. II. Role of gastrin in gastric epithelial cell proliferation and maturation. American Journal of Hhysiology, Gastrointestinal and Liver Physiology. 291(5): G762$765,2006$.

JENSEN, R. T.; COLLEN, M. J.; PANDOL, S. J.; ALLENDE, H. D.; RAUFMAN, J. P.; BISSONNETTE, B. M.; DUNCAN, W. C.; DURGIN, P. L.; GILLIN, J. C.; GARDNER, J. D. Cimetidine-induced impotence and breast changes in patients with gastric hypersecretory states. New England Journal of Medicine. 308(15): 883-887, 1983.

KEOGAN, D. M.; GRIFFITH, D. M. Current and potential applications of bismuth-based drugs. Molecules. 19(9): 15258-15297, 2014.

KLOTZ, U. Pharmacokinetic considerations in the eradication of Helicobacter pylori. Clinical Pharmacokinetics. 38(3): 243-270, 2000.

KNIGGE, U.; DEJGAARD, A.; WOLLESEN, F.; INGERSLEV, O.; BENNETT, P.; CHRISTIANSEN, P. M. The acute and long term effect of the H2-receptor antagonists cimetidine and ranitidine on the pituitary-gonodal axis in men. Clinical Endocrinology (Oxford). 18(3): 307-313, 1983.

KONTUREK, S. J.; RADECKI, T.; PIASTUCKI, I.; DROZDOWICZ, D. Advances in the understanding of the mechanism of cytoprotective action by colloidal bismuth subcitrate. Scandinavian Journal of Gastroenterology. 122(Supplement): 6-10, 1986.

KULAKSIZ, H.; ARNOLD, R.; GOKE, B.; MARONDE, E.; MEYER, M.; FAHRENHOLZ, F.; FORSSMANN, W. G.; EISSELE, R. Expression and cellspecific localization of the cholecystokinin B/gastrin receptor in the human stomach. Cell and Tissue Research. 299(2): 289-298, 2000.

KWOK, C. S.; ARTHUR, A. K.; ANIBUEZE, C. I.; SINGH, S.; CAVALLAZZI, R.; LOKE, Y. K. Risk of Clostridium difficile infection with acid suppressing drugs and antibiotics: meta analysis. The American Journal of Gastroenterology. 
107(7): 1011-1019, 2012.

KSIADZYNA, D.; SZELAG, A.; PARADOWSKI, L. Overuse of proton pump inhibitors. Polskie Archiwum Medycyny Wewnętrznej. 125(4): 289-298, 2015.

LAMBERT, J. R.; MIDOLO, P. The actions of bismuth in the treatment of Helicobacter pylori infection. Alimentary Pharmacology and Therapeutics. 11(Suppl 1): 27-33, 1997.

LEE, S. P. A potential mechanism of action of colloidal bismuth subcitrate: diffusion barrier to hydrochloric acid. Scandinavian Journal of Gastroenterology. 80(Suppl): 17-21, 1982.

LEE, S.P. The mode of action of colloidal bismuth subcitrate. Scandinavian journal of gastroenterology. 185: 1-6, 1991.

LEROTIĆ, I.; BARŠIĆ, N.; STOJSAVLJEVIĆ, S.; DUVNJAK, M. Acid inhibition and the acid rebound effect. Digestive Diseases. 29(5): 482-486, 2011.

LI X. Q.; ANDERSSON, T. B.; AHLSTRÖM, M.; WEIDOLF, L. Comparison of inhibitory effects of the proton pump-inhibiting drugs omeprazole, esomeprazole, lansoprazole, pantoprazole, and rabeprazole on human cytochrome P450 activities. Drug Metabolism and Disposition. 32(8): 821$827,2004$.

LUNDELL, L.; VIETH, M.; GIBSON, F.; NAGY, P.; KAHRILAS, P. J. Systematic review: the effects of long-term proton pump inhibitor use on serum gastrin levels and gastric histology. Alimentary Pharmacology and Therapeutics. 42(6): 649-663, 2015.

MASCLEE, G. M.; COLOMA, P. M.; KUIPERS, E. J. STURKENBOOM, M. C. Increased risk of microscopic colitis with use of proton pump inhibitors and non-steroidal anti-inflammatory drugs. The American Journal of Gastroenterology. 110(5): 749-759, 2015.

MATON, P. N.; BURTON, M. E. Antiacids revised: A review of their clinical pharmacology and recommended therapeutic use. Drugs. 57(6): 855-870, 1999. 
McCARTHY, D. M. Sucralfate. The New England Journal of Medicine. 325(14): 1017-1025, 1991.

MEHTA, A.; MEHTA, D.; LOGANATHAN, J.; PALADUGU, N.; BHALODKAR, N.C. Clopidogrel with proton pump inhibitors: safe or not? Clinical Cardiology. 34(9): 528-531, 2011.

NAGASHIMA, R.; YOSHIDA, N. Sucralfate, a basic aluminum salt of sucrose sulfate. I. Behaviors in gastroduodenal pH. Arzneimittelforschung. 29(11): 1668-1676, 1979.

NELIS, G. F.; VAN DE MEENE, J. G. Comparative effect of cimetidine and ranitidine on prolactin secretion. Postgraduate Medical Journal. 56(657): 478-480, 1980.

NELIS, G. F.; VAN DE MEENE, J. G. The effect of oral cimetidine on the basal and stimulated values of prolactina, thyroid stimulating hormone, follicle stimulating hormone and luteinizing hormone. Postgraduate Medical Journal. 56(651): 26-29, 1980.

PEDEN, N. R.; BOYD, E. J.; BROWNING, M. C.; SAUNDERS, J.H.; WORMSLEY, K. G. Effects of two histamine H2-receptor blocking drugs on basal levels of gonadotrophins, prolactin, testosterone ando estradiol-17 beta during treatment of duodenal ulcer in male patients. Acta Endocrinologica (Copenh). 96(4): 564-568, 1981.

PEDEN, N. R.; WORMSLEY, K. G. Effect of cimetidine on gonadal function in man. British Journal of Clinical Pharmacology. 14(4): 565, 1982.

PETERSON, W. L.; CIOCIOLA, A. A.; SYKES, D. L.; MCSORLEY, D. J.; WEBB, D. D. Ranitidine bismuth citrate plus clarithromycin is effective for healing duodenal ulcers, eradicating $\mathrm{H}$. pylori and reducing ulcer recurrence. RBC H. pylori Study Group. Alimentary Pharmacology and Therapeutics. 10(3): 251-261, 1996.

PIPKIN, G. A.; MILLS, J. G.; KLER, L.; DIXON, J. S.; WOOD, J. R. The safety of ranitidine bismuth citrate in controlled clinical studies. Pharmacoepidemiology and Drug Safety. 5(6): 399-407, 1996. 
SCHENTAG, J. J.; CERRA, F. B.; CALLERI, G.; DEGLOPPER, E.; ROSE, J. Q.; BERNHARD, H. Pharmacokinetic and clinical studies in patients with cimetidine-associated mental confusion. Lancet. 1(8109): 177-181, 1979.

SCHMITZ, F.; GOKE, M. N.; OTTE, J. M.; SCHRADER, H.; REIMANN, B.; KRUSE, M. L.; SIEGEL, E. G.; PETERS, J.; HERZIG, K. H., FOLSCH, U. R.; SCHMIDT, W. E. Cellular expression of CCK-A and CCK-B/gastrin receptors in human gastric mucosa. Regulatory Peptides. 102(2-3): 101-110, 2001.

SCHUBERT M. L.; PEURA, D. A. Control of gastric acid secretion in health and disease. Gastroenterology. 134(7): 1842-1860, 2008.

SCHUBERT, M.L. Gastric secretion. Current Opinion in Gastroenterology. 26(6): 598-603, 2010.

SHEEN, E.; TRIADAFILOPOULOS, G. Adverse effects of long-term proton pump inhibitor therapy. Digestive Diseases and Sciences. 56(4): 931-950, 2011.

SHI, S.; KLOTZ U. Proton pump inhibitors: an uptade of their clinical use and pharmacokinetics. European Journal of Clinical Pharmacology. 64(10): 935951, 2008.

SHIN, J. M.; KIM, N. Pharmacokinetics and pharmacodynamics of the proton pump inhibitors. Journal of Neurogastroenterology and Motility. 19(1): 25$35,2013$.

SHIN, J. M., SACHA, G. Pharmacology of proton pump inhibitors. Current Gastroenterology Reports. 10(6): 528-534, 2008.

SHIN, J. M.; MUNSON, K.; VAGIN, O.; SACHS, G. The gastric HK-ATPase: structure, function, and inhibition. Pflügers Archiv. 457(3): 609-622, 2009.

SLOMIANY, B. L.; KASINATHAN, C.; SLOMIANY, A. Lipolytic activity of Campylobacter pylori: effect of colloidal bismuth subcitrate (DeNol). American Journal of Gastroenterology. 84(10): 1273-1277, 1989.

SOLL, A. H.; WOLLIN, A. Histamine and cyclic AMP in isolated canine parietal cells. American Journal of Physiology. 237(5): E444-450, 1979. 
SOMOGYI, A.; GUGLER, R. Clinical pharmacokinetics of cimetidine. Clinical Pharmacokinetics. 8(6): 463-495, 1983.

SOX, T. E.; OLSON, C. A. Binding and killing of bacteria by bismuth subsalicylate. Antimicrobial Agents and Chemotherapy. 33(12), 1989.

STABleS, R.; CAMPBELL, C. J.; CLAYTON, N. M.; CLITHEROW, J. W.; GRINHAM, C. J.; MCCOLM, A. A.; MCLAREN, A.; TREVETHICK, M. A. Gastric anti-secretory, mucosal protective, anti-pepsin and anti-Helicobacter properties of ranitidine bismuth citrate. Alimentary Pharmacology and Therapeutics. 7(3): 237-246, 1993.

STEDMAN, C. A. M.; BARCLAY, M. L. Review article: comparison of the pharmacokinetics, acid suppression and efficacy of proton pump inhibitors. Alimentary Pharmacology and Therapeutics. 14(8): 963-978, 2000.

SZABO, S. Gastric cytoprotection is still relevant. Journal of Gastroenterology and Hepatology. 29(Suppl. 4): 124-132, 2014.

TANAKA, S.; GUTH, P. H.; PAULSEN, G.; KAUNITZ, J. D. Gastroprotective effect of ranitidine bismuth citrate is associated with increased mucus bismuth concentration in rats. Gut. 39(2): 164-171, 1996.

TAKEUCHI, K.; KOYAMA, M.; HAYASHI, S.; AIHARA, E. Prostagladin EP receptor subtypes involved in regulating $\mathrm{HCO}(3)(-)$ secretion from gastroduodenal mucosa. Current Pharmaceutical Design. 16(10): 12411251, 2010.

TARI, A.; KAMIYASU, T.; YONEI, Y.; HAMADA, M.; SUMII, M.; SUMII, K.; KAJIYAMA, G.; DIMALINE, R. Role of gastrin/CCK-B receptor in the regulation of gastric acid secretion in rat. Digestive Diseases and Sciences. 42(9): 1901-1907, 1997.

TOMMERAS, K.; HAMMER, P.; SUNDLER, F.; BORCH, K.; MARDH, S.; CABERO, J. L. Immunolocalization of cholecystokinin-2 receptors in rat gastric mucosa. Scandinavian Journal of Gastroenterology. 37(9): 10171024, 2002. 
VAKILY, M.; ZHANG, W.; WU, J.; ATKINSON, S. N.; MULFORD, D. Pharmacokinetics and pharmacodynamics of a known active PPI with a novel dual delayed release techonology, dexlansoprazole MR: a combined analysis of randomized clinical trials. Current Medical Research and Opinion. 25(3): 627-638, 2009.

VUYYURU, L.; SCHUBERT, M. L.; HARRINGTON, L.; ARIMURA, A.; MAKHLOUF, G. M. Dual inhibitory pathways link antral somatostatin and histamine secretion in human, dog, and rat stomach. Gastroenterology. 109(5): 1566-1574, 1995.

VUYYURU, L., HARRINGTON, L.; ARIMURA, A.; SCHUBERT, M. L. Reciprocal inhibitory paracrine pathways link histamine and somatostatin secretion in the fundus of the stomach. American Journal of Physiology. 273(1): G106-111, 1997.

YU, E. W.; BAUER, S. R.; BAIN, P. A.; BAUER, D. C. Proton pump inhibitors and risk of fractures: a meta-analysis of 11 international studies. The American Journal of Medicine. 124(6): 519-526, 2011.

WEDEMEYER, R. S.; BLUME, H. Pharmacokinetic drug interaction profiles of proton pump inhibitors: an uptade. Drug Safety. 37(4): 201-211, 2014. 
